\title{
Prostate Cancer by AJCC v7 Stage
}

National Cancer Institute

\section{Source}

National Cancer Institute. Prostate Cancer by A/CC v7 Stage. NCI Thesaurus. Code C91233.

A term that refers to the staging of prostate carcinoma according to the American Joint Committee on Cancer, 7 th edition. 